\title{
ACCION ANTIMICROBIANA DE ALGUNAS PLANTAS DE USO MEDICINAL EN CHILE. I.
}

\author{
Waldo Lazo \\ Laboratorio de Botánica Criptogámica \\ Departamento de Ciencias Ecológicas \\ Facultad de Ciencias, Universidad de Chile
}

Palabras clave: antimicrobiano, plantas.

Key words: antimicrobial, plants.

\section{RESUMEN}

El desarrollo de Staphylococcus aureus y Bacillus subtilis fue inhibido por la decocción y el eatracto en etanol de cáscara de frutos de Punica granatum $L$., raiz de Geum quellyon Sweet, corteza de Quillaja saponaria Mol.; la decocción y el extracto en acetato de etilo de cotiledones de Lucuma bifera Mol.; la decocción y el extracto en etanol o acetato de etilo de hojas y tallos de Calceolaria thyrsiflora Graham, Sphacele salviae (Lindl.) Briq. Haplopappus baylahuen Remy y la decocción y los extractos en etanol, acetato de etilo y cloroformo de Luma chequen (Mol.) A. Gray. El desamollo de Escherichia coli fue escasamente inhibido por el extracto en acetato de etilo de cotiledones de L. bifera $\mathrm{Mol}$. El desarrollo de Acremonium falciforme fue inhibido por la decocción y los extractos en etanol o acetato de etilo de hojas y tallos de $\mathrm{C}$. thyrsiflora $y \mathrm{H}$. baylahuen $y$ por los extractos en etanol o acetato de etilo de hojas y tallos de S. salviae. Ninguna de las decocciones o extractos inhibió el desarnollo de Candida albicans.

La acción antimicrobiana de plantas chilenas ha sido estudiada por diversos investigadores. Entre ellos Bhakuni, Bittner y col. (1974). Montes \& Wilkomirsky (1985). Lazo (1987) dio a conocer sus resultados sobre la acción antimicótica de algunas plantas chilenas. Lazo y Ravena (1989) informaron sobre la acción antibacteriana y antimicótica de algunas especies del género Nothoscordum. Vigneau (1985) en "Plantes Medicinales", dedica muchas páginas a los antimicrobianos producidos por plantas de diversos países.

\section{SUMMARY}

[Antimicrobial action of some plants of medicinal use in Chile]

The growth of Staphylococcus aureus and Bacillus subtilis was inhibited by the decoction and ethanol extract of Punica granatum $L$. rind, Geum quellyon Sweet root, Quillaja saponaria Mol. cortex; the decoction and ethyl acetate extract of Lucuma bifera Mol. cotyledons; decoction and ethanol or ethyl acetate extract of leaves and stems of Calceolaria thyrsiflora Graham, Sphacele salviae (Lindl.) Briq., Haplopappus baylahuen Remy and the decoction, ethanol, ethyl acetate and chloroform extract of Luma chequen (Mol.) A. Gray leaves. The growth of Escherichia coli was poorly inhibited by the ethyl acetate extract of $\mathrm{L}$. bifera cotyledons. The growth of Acremonium falciforme was inhibited by the decoction and ethanol or ethyl acetate extract of leaves and stems of $\mathrm{C}$. thyrsiflora and $\mathrm{H}$. bay. lahuen and by the ethanol or ethyl acetate extract of leaves and stems of S. salviae. None of the decoctions or extracts inhibited the growth of Candida albicans.

Esta comunicación es parte de un estudio que se realiza con diversas plantas de uso medicinal en Chile (Hochstetter, 1983); Montes \& Wilkomirsky (1985), para dar a conocer las acciones antimicrobianas in vitro que algunas de ellas presentan.

\section{MATERIALES Y METODOS}

Se preparó decocciones de diversas plantas de uso medicinal que, para ese fin se expenden en 


\section{Cuadro 1}

Acción antimicrobiana de los extractos de plantas estudiados in vitro.

\begin{tabular}{|c|c|c|c|c|c|}
\hline & S. aureus & B. subtilis & E. coli & C. albicans & A. falciforme \\
\hline \multicolumn{6}{|c|}{ P. granatum (cáscara de frutos) } \\
\hline decocción & + & + & - & - & - \\
\hline e. etanol & + & + & $\cdot$ & - & - \\
\hline \multicolumn{6}{|l|}{ L. bifera (cotiledones) } \\
\hline decocción & + & + & - & - & - \\
\hline e. acetato de etilo & + & + & $(+-)$ & - & - \\
\hline \multicolumn{6}{|l|}{ G. quellyon (raíz) } \\
\hline decocción & + & + & - & - & - \\
\hline e. etanol & + & + & - & - & $\cdot$ \\
\hline \multicolumn{6}{|l|}{ L. chequen (hojas) } \\
\hline decocción & + & + & - & - & - \\
\hline c. etanol & + & + & - & - & - \\
\hline e. acetato de etilo & + & + & & - & - \\
\hline e. cloroformo & + & + & - & $\cdot$ & $\cdot$ \\
\hline \multicolumn{6}{|c|}{ C. thyrsiflora (hojas, tallos) } \\
\hline decocción & + & + & - & - & + \\
\hline e. etanol & + & + & .. & - & $(+-)$ \\
\hline e. acetato de etilo & + & + & - & $\cdot$ & + \\
\hline \multicolumn{6}{|l|}{ S. salviae (hojas, tallos) } \\
\hline decocción & + & + & - & - & $\cdot$ \\
\hline e. etanol & + & + & . & - & $(+-)$ \\
\hline e. acetato de etilo & + & + & & - & + \\
\hline \multicolumn{6}{|c|}{ H. baylahuen (hojas, tallos) } \\
\hline decocción & + & + & - & - & + \\
\hline e. etanol & + & + & & - & $(+-)$ \\
\hline e. acetato de etilo & + & + & & - & $(+-)$ \\
\hline \multicolumn{6}{|l|}{ Q. saponaria (corteza) } \\
\hline decocción & + & + & - & - & - \\
\hline e. ctanol & + & + & - & - & - \\
\hline
\end{tabular}

$+\quad=\quad$ inhibición total del desarrollo.

- $=$ no inhibe el desarrollo.

$(+-),=$ inhibición escasa o parcial del desarrollo. 
sobres en las farmacias y yerberías, haciendo hervir al Baño María durante cinco minutos diez gramos de cada una de ellas en ochenta ml de agua destilada estéril. Se dejó enfriar, se tomó el pH de cada decocción y se ajustó a pH 6, cuando fue necesario. $\mathrm{Si}$ en las pruebas siguientes, alguna de las decocciones evidenció una acción antibacteriana o antimicótica, se sometió muestras de la planta en cuestión a extracción durante 24 horas con etanol, cloroformo, acetato de etilo, éter etílico, hexano, acetona (10 gramos de planta con $50 \mathrm{ml}$ de solvente) (Lazo, 1987). Se averiguó la acción que esas decocciones y extractos ejercían sobre el desarrollo de Staphylococcus aureus, Bacillus subtilis, Escherichia coli, Acremonium falciforme y Candida albicans.

La prueba de la acción antimicótica se realizó en placas de Petri en las que se vertió una delgada capa de agar nutriente dextrosa inoculada con el hongo respectivo $\left(10^{4} \mathrm{UFC} / \mathrm{ml}\right.$ concentración final). Para estudiar la acción antibacteriana se procedió en la misma forma $\left(10^{5} \mathrm{UFC} / \mathrm{ml}\right.$ concentración final), pero, se usó agar nutriente solo, sin añadirle dextrosa. En el agar solidificado se practicó excavaciones de diez milímetros de diámetro y se las rellenó con cada una de las decocciones. Cuando se probó los extractos en solventes químicos, se mojó discos de papel filtro de $5 \mathrm{~mm}$ de diámetro en cada uno de esos extractos, $y$, una hora más tarde, cuando el solvente se había evaporado totalmente, se depositó cada disco sobre la superfi- cie del agar. Se incubó a $35^{\circ} \mathrm{C}$ durante 24 horas las placas con S. aureus, E. coli, B. subtilis, C. albicans y durante 48 horas las placas con A. falciforme.

\section{RESULTADOS}

Inhibieron el desarrollo de $\mathbf{S}$. aureus y $\mathbf{B}$. subtilis (Foto 1), la decocción y el extracto en etanol de cáscara de frutos de Punica granatum L., raíz de Geum quellyon Sweet, corteza de Quillaja saponaria Mol.; la decocción y el extracto de acetato de etilo de cotiledones trozados de Lucuma bifera Mol.; la decocción y el extracto en etanol o acetato de etilo de hojas y tallos de Calceolaria thyrsiflora Graham, Sphacele salviae (Lindl.) Briq., Haplopappus baylahuen Remy y la decocción y los extractos en etanol, acetato de etilo y cloroformo de Luma chequen (Mol.) A. Gray. El desarrollo de E. coil fue escasamente inhibido por el extracto en acetato etilo de cotiledones trozados de L. bifera. El desarrollo de A. falciforme fue inhibido por la decocción y los extractos en etanol o acetato de etilo de hojas y tallos de $\mathbf{C}$. thyrsiflora y $\mathbf{H}$. baylahuen y por los extractos en etanol o acetato de etilo de hojas y tallos de S. salviae. Ninguna de las decocciones o extractos inhibió el desarrollo de C. albicans (Cuadro 1).

\section{AGRADECIMIENTOS}

El autor expresa su gratitud a los Drs. Guido Pincheira y Luis Corcuera por haberle permitido usar equipos e instrumental científico de sus laboratorios y al Prof. Manuel Mahú por haber revisado la identificación de las plantas estudiadas.

\section{REFERENCIAS}

Bhakuni D. S., M. Bittner, C. Marticorena, M. Silva, E. Weldt and Melo M.E. and Zemelman, R. (1974). Screening of Chilean plants for antimicrobial activity. Lloydia 37: 621632.

Hochsteter, F. (1983). Las Hierbas Medicinales y la Salud. Ed. Hochsteter Ltda., Santiago.

Lazo, W. (1987). Acción antimicótica de algunas plantas chilenas. Bol. Micol. 3: 191-193.
Lazo, W., P. Ravena. (1989). Acción antimicrobianba de tres especies del género Nothoscordum (Allianceae). Bol. Micol. 4: 91-92.

Montes M., Wilkomirsky, T. (1985). Medicina Tradicional Chilena. Ed. Universidad de Concepción, Concepción.

Vigneau, C. (1985). Plantes Medicinales. Ed. Masson, Paris. 


\section{Foto 1}

Acción de los extractos de diversas plantas sobre el desarrollo de Staphylococcus aureus a las 24 horas de incubación a $35^{\circ}$ C.: P. Extracto en etanol de cáscara de frutos de P. granatum. S. Extracto en acetato de etilo de S. salviae. C. Extracto en acetato de etilo de C. thyrsiflora. G. Extracto en etanol de G. quellyon. H. Extracto en acetato de etilo de H. baylahuen. L. Extracto en acetato de etilo de L. bifera. M. Extracto en acetato de etilo de $\mathbf{L}$. chequen.

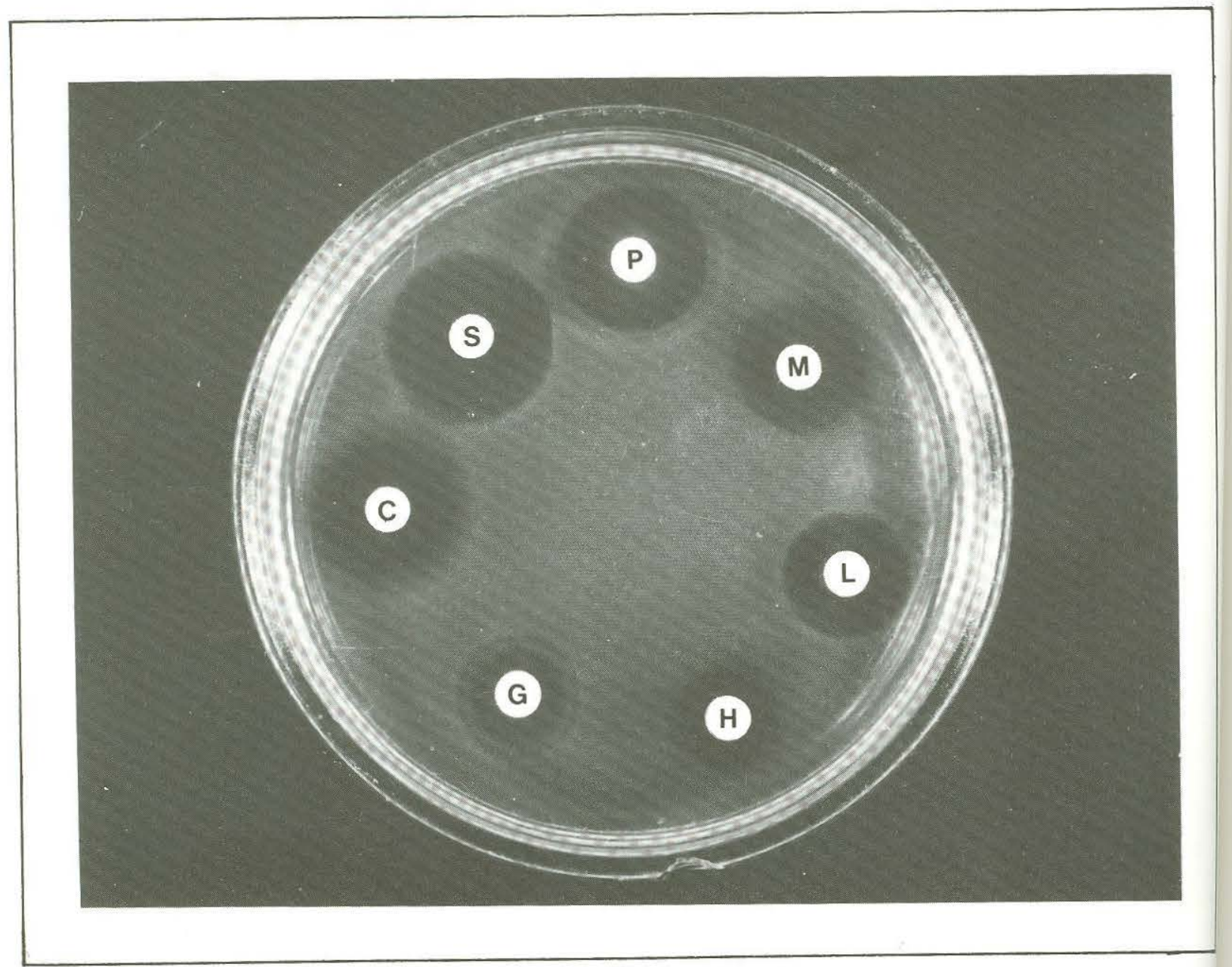

